Research Article

\title{
Emerging Nutritional Problem of Adult Population: Overweight/Obesity and Associated Factors in Addis Ababa City Communities, Ethiopia-A Community-Based Cross- Sectional Study
}

\author{
Tsedeke Wolde Hailemariam (D), Samrawit Solomon Ethiopia (D), \\ Andamlak Gizaw Alamdo $(\mathbb{D}$, and Haimanot Ewnetu Hailu (D) \\ Department of Public Health, St. Paul's Hospital Millennium Medical College (SPHMMC), Addis Ababa, Ethiopia \\ Correspondence should be addressed to Samrawit Solomon Ethiopia; samrawit.solomon@sphmmc.edu.et
}

Received 27 April 2020; Accepted 26 September 2020; Published 19 October 2020

Academic Editor: Mario Musella

Copyright (c) 2020 Tsedeke Wolde Hailemariam et al. This is an open access article distributed under the Creative Commons Attribution License, which permits unrestricted use, distribution, and reproduction in any medium, provided the original work is properly cited.

\begin{abstract}
Background. Obesity is an emerging public health problem in developing countries. There is limited study conducted in Ethiopia to determine the prevalence of obesity and its associated factors among adult population. Therefore, this study aimed at determining the prevalence of overweight/obesity and the associated factors among adults aged 25-64 years in Addis Ababa city community residents, Ethiopia. Methods. A community-based cross-sectional study was conducted from April 10, 2017, to May 20, 2017, in Addis Ababa. A total of 512 adults were recruited. A two-stage cluster followed by a systematic random sampling technique was used for sample selection. Data were collected using questionnaires and anthropometric measurements. The adjusted odds ratio (AOR) with a 95\% CI was reported to show the strength of association. A $P$ value $<0.05$ was considered statistically significant. Results. A total of 484 adults participated in the study with a response rate of $94.5 \%$. The prevalence of overweight and obesity among study participants was found to be 99 (21.5\%) and 14 (2.9\%), respectively. Males were $90 \%$ less likely to be obese when compared to females ( $\mathrm{AOR}=0.10$ (95\% CI: $0.01-0.84)$ ). Illiterate people were $94 \%$ less likely to be obese compared to those who were literate people $(A O R=0.06$ (95\% CI: $0.01-0.44)$ ). Nonhypertensive individuals were $86 \%$ less likely to be obese when compared to hypertensive ( $\mathrm{AOR}=0.14$ (95\% CI: 0.03-0.69)). Conclusion. The combined prevalence of overweight and obesity was found to be considerably high in Addis Ababa city residents compared to the national figure. Being female, literate, and presence of hypertension are independent predictors of overweight/obesity in the study population. Thus, the concerned bodies should initiate efforts to tackle the newly emerging public health problem of the country and promote healthy lifestyle behaviors in the inhabitants of city settings.
\end{abstract}

\section{Background}

Overweight and obesity are now stepping in to the borders of developing countries. Countries with a drastic shift from a state of undernutrition to overnutrition are facing chronic nutrition-related noncommunicable diseases (NCDs) such as cancer, hypertension, cardiovascular disease, and type two diabetes mellitus [1]. Various studies have shown that obesity and nutrition transition have been evident even in middle- and low-income countries of urban areas of sub-Saharan Africa. Following the nutrition transition and epidemiologic transition, chronic noncommunicable diseases are prevailing in the developing countries [2].

Most countries in Asia, Latin America, Northern Africa, the Middle East, and the urban areas of sub-Saharan Africa have all experienced a shift in the overall structure of their dietary pattern with related disease patterns over the last few decades. Major dietary change includes a large increase in the consumption of fat and added sugar in the diet, often a 
marked increase in animal food products contrasted with a fall in total cereal intake and fiber [3].

The obesogenic environment as evidenced by the consumption of high-energy-density diets and diets low in complex carbohydrates and a sedentary life style are known to be among the contributors to the developing problem of obesity [4]. The globalization of marketing, the emergence of new technologies, the international communication systems, and the access to transportation have been a potential for low- and middle-income countries to be victims of obesity and the associated problems at a faster rate $[4]$.

Even over the last 30 years, nutrition study in Ethiopia depicted that the urban population of Ethiopia are at risk of obesity. "Some groups of urban Ethiopians are in a phase of change of socioeconomic status, dietary habits, and physical work outputs towards a more Western pattern" [5]. The rise in obesity prevalence represents a challenge for the health care system, which is traditionally overburdened by underweight problems arising from famine, food insecurity, and infectious diseases [6], but now has to cope with obesityrelated NCDs which are estimated to account for $46 \%$ of all deaths by 2030 [7].

Many years ago, overweight and obesity were not an emerging problem in Ethiopia. However, nowadays, the level of overweight and obesity among adult population increased from $3 \%$ in 2000 to $8 \%$ in $2016[8,9]$. Similar studies showed that the magnitude of overweight ranges from $16.1 \%$ to $25.3 \%$ and that of obesity ranges from $5.6 \%$ to $16.2 \%$ [10-13]. A study conducted in Tanzania revealed that the prevalence of overweight and obesity among adults was $24.1 \%$ and $19.2 \%$, respectively [14]. A similar study conducted among the urban residents of adult Malawians showed that the prevalence of overweight/ obesity was found to be $28.1 \%$ [15].

In local studies conducted in different Ethiopian cities, the overall prevalence of overweight/obesity among adults in Gonder, Addis Ababa, Dessie, Hawassa, and Bahir Dar are found to be $48.6 \%, 35.9 \%, 28.5 \%, 28 \%$, and $11.3 \%$, respectively $[11,13,16-18]$. Another similar study conducted among permanent employees of the Commercial Bank of Ethiopia and teachers in the government schools of Addis Ababa found that $24.7 \%$ of men and $25.7 \%$ of women were overweight, and $2.1 \%$ men and $10.2 \%$ women were obese [19].

Few surveys have been conducted in Addis Ababa city to determine the magnitude of overweight/obesity, and its associated factors among adults aged 18-65 years have not yet been documented for this capital, and there is scarce information about the prevalence and determinants of overweight/obesity. Although there are circumstantial lines of evidence on the increasing level of obesity in the urban population of Ethiopia, there are no recent population-based studies which estimated its prevalence and associated factors given the specific cultural and life style milieu of the urban community in Ethiopia in general and in Addis Ababa city in particular.

The findings of this study can benefit the policy makers to design appropriate interventions in order to tackle the emerging problem of overweight/obesity and its associated factors among the study population. Generally, the study will provide preliminary information for further researches in the study area of obesity and its related noncommunicable diseases.

\section{Methods}

2.1. Study Setting, Design, and Period. The study was conducted in Addis Ababa city community residents which is the capital city of Ethiopia. The city is divided into 10 administrative subcities and 116 administrative woredas/districts. It is the largest city in Ethiopia with a population of $3,384,569$ people and annual growth rate of 3.8 people. The total population between age groups 15 and 64 years is 2,228,510 [20]. A community-based cross-sectional study was employed from April 10, 2017, to May 20, 2017.

2.2. Population and Sampling. The source population was all adult men and women aged 25-64 years who are living in Addis Ababa city during the study period. While the study population was all adult men and women aged 25-64 years who are living in Addis Ababa City for two years or longer, they were eligible to participate in the study. Pregnant women, mothers who were less than two-month postdelivery, women who were on hormonal contraception, and participants with physical deformity, edema, or wasting syndrome were excluded from the study.

The sample size was calculated using the formula for estimation of a single population $(n=((Z(1-\alpha / 2)) 2 \cdot p(1-p))$ / d2) with the following assumption: $z=$ standard normal variable at 95\% (1.96) level; $p=$ overall prevalence of overweight/obesity among adult population was $28 \%$ in Hawassa town [17]; $d=5 \%$ margin of error; the design effect number is multiplied by $1.5(\mathrm{De})$ and added to $10 \%$ of nonresponse rate. Hence, the minimum sample size for the study was 512 .

A two-stage cluster sampling method was used for sample selection. The primary sampling units were subcities randomly selected from each of the ten study subcities. A total of three subcities were selected from the ten subcities. Secondary sampling units were districts randomly selected from subcities selected for the study. Two districts were randomly selected from each of the study three subcities, and a total of six districts were selected for the study. A systematic sampling was used to identify the households selected for the study. The sample size was drawn from each district was proportional to the population size of the district. Within the selected households, lottery method was used to identify the study participants, and only one sample was drawn from each household.

2.3. Data Collection Procedures and Measurements. A structured questionnaire was used to collect sociodemographic (age, sex, occupation, marital status, level of educational, monthly income, wealth index, and family size), life style (history of tobacco and drug use, alcohol consumption, history of hypertension, history of diabetes mellitus, and status of physical activity), anthropometric measurements (weight and height), and assessment of dietary intake. A standardized questionnaire designed by WHO steps 
instruments for chronic disease risk surveillance questionnaire was used after minor modifications [21]. All the data was collected using this questionnaire by face-to-face interview.

Dietary diversity data was collected using a modified individual dietary diversity questionnaire as recommended by Food and Agricultural Organization (FAO) 2008 [22]. Dietary diversity was assessed by asking respondents to report the different food groups they consumed over the past 24 hours, and the tercile and the mean dietary diversity score of the group was calculated and used in the analysis. Dietary diversity was a diverse food composition which included consumption of all the food categories. This category was divided into three low $(<3)$, medium (4-6), and high $(\geq 7)$ dietary diversity scores [22].

Weight and height are the main anthropometric measurements that were used in this study. Weight was measured to the nearest $0.1 \mathrm{~kg}$ without shoe and wearing light clothing. Height was measured by positioning the subject in the Frankfort plane using a stadiometer. Study participants were in barefoot while measuring their height. Body mass index (BMI) was calculated as weight in kilograms divided by height in meters squared $\left(\mathrm{kg} / \mathrm{m}^{2}\right)$ [23]. The overweight is set between a BMI of 25 and $29.99 \mathrm{~kg} / \mathrm{m}^{2}$ and obese is defined as a BMI $\geq 30 \mathrm{~kg} / \mathrm{m}^{2}$ [23]. The outcome variable was dichotomized as overweight and obese (yes) compared to the reference of normal and underweight groups (no).

2.4. Data Quality Control. A 5\% of pretest of the sample size was carried out to check for validity and the reliability of the questionnaire before the commencement of the main data collection and it was found to be valid and reliable for the study participants. People who were included in the pretest are not part of the main study. Data collectors are thoroughly being trained and briefed about the data collection so that they can come up with valid data. The anthropometric measurement was conducted by diploma nurses. There is a continuous supervision during the data collection.

2.5. Data Management and Analysis. Study questionnaires were kept in binders during interview process; all questionnaires collected each day were packed in an envelope and submitted to supervisor's review and feedback. All reviewed and completed questionnaires were stored under lock in canvas bag and kept with the supervisors. Upon completion of the data collection, all filled questionnaires were submitted to the principal investigator (PI). Principal investigator and supervisors were once again checking the questionnaires for completeness and consistency and identify any incomplete questionnaires.

Epi Info data entry template was developed by PI. Then two data encoders (B.S. degree in computer science and data entry experience using Epi Info data and SPSS) were trained for two days on data entry template by PI. Then, data was entered by the two data personnel who were entering independently in Epi Info data-based data entry template (double data entry). Then, the PI has carried out data cleaning. Then, questionnaires of cases with discrepancies were used to check the points of discrepancy and correct according to the data recorded on the questionnaire till all discrepancies were cleaned. Then, the cleaned data set was exported to SPPS.

Data was entered, cleaned, and analyzed using Epi Info version 7 and SPSS version 23. All categorical variables were analyzed using frequencies and percentages. Cross tabulations and Pearson's chi-square test were used to obtain the associations and strength of relationship between the independent and the dependent variables. Logistic regression analysis was used to control for confounding factors. In this model, the dependent variable was BMI while the independent variables were factors that showed statistical significance on chi-square test and on univariate analysis including age, sex, marital status, level of education, occupation, wealth index, morbidity status, dietary diversity score, and physical activity level. A $P$ value of $\leq 0.05$ was considered significant. The crude odds ratio (COR) and adjusted odds ratio (AOR) with a 95\% CI were reported to show the strength of association. A $P$ value $<0.05$ was considered statistically significant.

2.6. Ethical Issues. Ethical clearance was obtained from the Institution Review Board (IRB) of the St. Paul's Hospital Millennium Medical College (SPHMMC). Every study participant was briefed about the research intent and was asked for permission to participate on his or her own will and was informed that he or she was not missing anything for the denial to participate in the study. Informed consent was obtained from all participants in the study. The participants were reassured about confidentiality of the data.

\section{Results}

3.1. Characteristics of Study Participants. A total of 484 participants were involved in this study from 512 participants planned to be included in the study, giving a response rate of $95 \%$. From the 484 participants, 253 (52.3\%) were men and $231(47.7 \%)$ were women, giving a men to women ratio of 1:0.9. The mean $( \pm \mathrm{SD})$ age of the study participants was $35.19( \pm 8.76)$ years. More than half of the study participants, 268 (55.4\%), were under the age of 35 years. From the study participants, $361(74.6 \%)$ were Orthodox, and 71 $(14.7 \%)$ were Protestants. The majority of the study subjects, 259 (53.5\%), were Amhara, followed by Oromo 117 (24.2\%) and Tigre 45 (9.3\%) (Table 1).

The majority of the study participants, 337 (69.6\%), had completed or were attending college or university education and $16(3.3 \%)$ of the study subjects had no formal schooling. Fiftynine $(12.2 \%)$ of the study subjects have completed or attended high school education and the rest 72 (14.9\%) had junior- or elementary-level education. More than half, 268 (55.4\%), of the study participants were married, and 184 (38\%) were single. Around one-third, 179 (37\%), of the study participants were government employees. Housewives accounted for 37 (7.6\%) and merchants accounted for 146 (30.2\%) (Table 1).

Around three-fourths, 344 (71.1\%), of the study participants had four-person family size. The mean $( \pm S D)$ 
TABLE 1: The sociodemographic characteristics of the adult population in Addis Ababa, Ethiopia.

\begin{tabular}{|c|c|c|}
\hline Variables $(n=484)$ & Frequency & Percent \\
\hline \multicolumn{3}{|l|}{ Sex } \\
\hline Male & 253 & 52.3 \\
\hline Female & 231 & 47.7 \\
\hline \multicolumn{3}{|l|}{ Age groups } \\
\hline $25-34$ & 268 & 55.4 \\
\hline $35-44$ & 150 & 31 \\
\hline $45-54$ & 42 & 8.7 \\
\hline $55-64$ & 24 & 5 \\
\hline \multicolumn{3}{|l|}{ Religion } \\
\hline Orthodox & 361 & 74.6 \\
\hline Protestant & 71 & 14.7 \\
\hline Muslim & 47 & 9.7 \\
\hline Other & 5 & 1 \\
\hline \multicolumn{3}{|l|}{ Ethnicity } \\
\hline Amhara & 259 & 53.5 \\
\hline Oromo & 117 & 24.2 \\
\hline Tigre & 45 & 9.3 \\
\hline Gurage & 35 & 7.2 \\
\hline Wolaita & 22 & 4.5 \\
\hline Others & 6 & 1.2 \\
\hline \multicolumn{3}{|l|}{ Marital status } \\
\hline Married & 268 & 55.4 \\
\hline Single & 184 & 38 \\
\hline Divorced & 20 & 4.1 \\
\hline Widowed & 12 & 2.5 \\
\hline \multicolumn{3}{|l|}{ Educational status } \\
\hline No school & 16 & 3.3 \\
\hline Elementary (1-6) & 43 & 8.9 \\
\hline Junior (7-8) & 29 & 6 \\
\hline High school (9-12) & 59 & 12.2 \\
\hline College and above & 337 & 69.6 \\
\hline \multicolumn{3}{|l|}{ Occupation } \\
\hline Housewife & 37 & 7.6 \\
\hline Merchant & 146 & 30.2 \\
\hline Government employee & 179 & 37 \\
\hline Non-government employee & 80 & 16.5 \\
\hline Others & 42 & 8.7 \\
\hline \multicolumn{3}{|l|}{ Monthly income (birr) } \\
\hline$<8000$ & 277 & 57.2 \\
\hline$\geq 8000$ & 207 & 42.8 \\
\hline \multicolumn{3}{|l|}{ Wealth index tercile (HH) } \\
\hline Low & 170 & 35.1 \\
\hline Medium & 167 & 34.5 \\
\hline High & 147 & 30.4 \\
\hline
\end{tabular}

monthly income of the study participants was 8154.53 $( \pm 5502.31)$ Ethiopian birr per month. More than half, 277 (57.2\%), of the study participants have earned less than or equal to 8000 Ethiopian birr per month. While from the study participants, 170 (35.1\%) were of low-tercile or socioeconomic status (SES) of households, and 147 (30.4\%) were of high-tercile households (Table 1).

3.2. Prevalence of Overweight and Obesity and Their Sociodemographic Association. The mean $( \pm \mathrm{SD})$ body mass index (BMI) of the study participants was $23.06( \pm 3.35) \mathrm{kg} / \mathrm{m}^{2}$. The

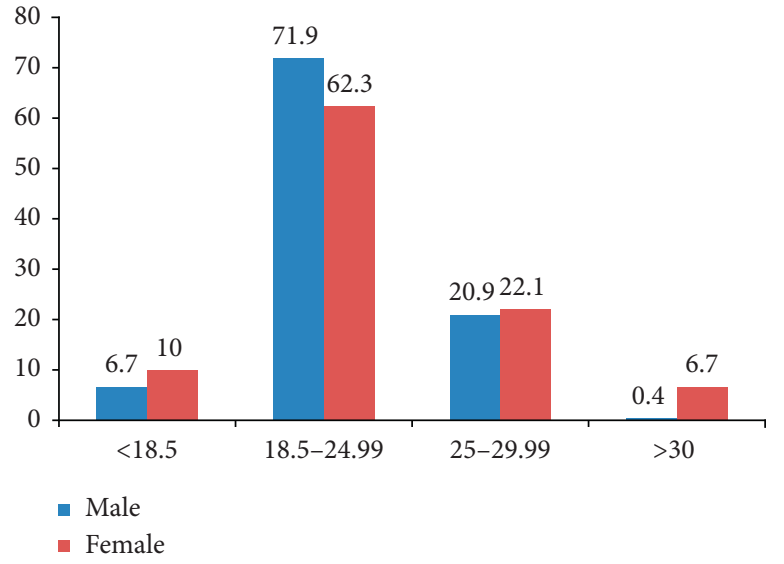

Figure 1: Classification of nutritional status using body mass index (BMI) among adults in Addis Ababa, Ethiopia.

TABle 2: Prevalence of obesity by sociodemographic characteristics of study participants in Addis Ababa, Ethiopia.

\begin{tabular}{|c|c|c|c|}
\hline \multirow[b]{2}{*}{ Variables $(n=484)$} & \multicolumn{2}{|c|}{ Nutritional status $(N=14)$} & \multirow[b]{2}{*}{$P$ value } \\
\hline & $\begin{array}{c}\text { Obese } \\
\text { Number (\%) }\end{array}$ & $\begin{array}{c}\text { Nonobese } \\
\text { Number (\%) }\end{array}$ & \\
\hline $\begin{array}{l}\text { Age groups } \\
25-34 \\
35-44 \\
45-54 \\
55-64 \\
\end{array}$ & $\begin{array}{l}3(1.1) \\
5(3.3) \\
4(9.5) \\
2(8.3) \\
\end{array}$ & $\begin{array}{l}265(98.9) \\
145(96.7) \\
38(90.5) \\
22(91.7) \\
\end{array}$ & 0.007 \\
\hline $\begin{array}{l}\text { Sex } \\
\text { Male } \\
\text { Female } \\
\end{array}$ & $\begin{array}{c}1(0.4) \\
13(5.6) \\
\end{array}$ & $\begin{array}{l}252(99.6) \\
218(94.4) \\
\end{array}$ & 0.001 \\
\hline $\begin{array}{l}\text { Marital status } \\
\text { Married } \\
\text { Single } \\
\text { Divorced } \\
\text { Widowed }\end{array}$ & $\begin{array}{c}10(3.7) \\
0(0) \\
2()(10) \\
2(16.7)\end{array}$ & $\begin{array}{c}258(96.3) \\
184(100) \\
18(90) \\
10(83.3) \\
\end{array}$ & $<0.0001$ \\
\hline $\begin{array}{l}\text { Family size } \\
\leq 4 \\
>4\end{array}$ & $\begin{array}{l}9(2.6) \\
5(3.6) \\
\end{array}$ & $\begin{array}{l}335(97.4) \\
135(96.4)\end{array}$ & $>0.05$ \\
\hline $\begin{array}{l}\text { Occupation } \\
\text { Housewife } \\
\text { Merchant } \\
\text { GE } \\
\text { Non-GE } \\
\text { Other }\end{array}$ & $\begin{array}{l}2(5.4) \\
9(6.2) \\
2(1.1) \\
1(1.3) \\
0(0)\end{array}$ & $\begin{array}{c}35(94.6) \\
137(93.8) \\
177(98.9) \\
79(98.8) \\
42(100)\end{array}$ & 0.034 \\
\hline $\begin{array}{l}\text { Monthly income } \\
<8000 \text { birr } \\
\geq 8000 \text { birr }\end{array}$ & $\begin{array}{l}5(2.1) \\
9(4.3) \\
\end{array}$ & $\begin{array}{l}230(97.9) \\
198(95.7) \\
\end{array}$ & $>0.05$ \\
\hline $\begin{array}{l}\text { Have car } \\
\text { No } \\
\text { Yes }\end{array}$ & $\begin{array}{c}7(2) \\
7(5.5) \\
\end{array}$ & $\begin{array}{c}349(98) \\
121(94.5) \\
\end{array}$ & 0.043 \\
\hline $\begin{array}{l}\text { Wealth index (SES) } \\
\text { Low } \\
\text { Medium } \\
\text { High }\end{array}$ & $\begin{array}{c}1(0.6) \\
3(1.8) \\
10(6.2)\end{array}$ & $\begin{array}{l}169(99.4) \\
164(98.2) \\
137(93.2)\end{array}$ & 0.003 \\
\hline
\end{tabular}

$\mathrm{GE}=$ government employee. $S E S=$ socioeconomic status. $P$ values refer to the chi-squared test for the difference observed between obese and nonobese participants. 
median with range of BMI was $23.03(15.43-36.85) \mathrm{kg} / \mathrm{m}^{2}$. According to WHO adult BMI classification, the combined prevalence of adult overweight and obesity was $24.4 \%$, the specific prevalence being $2.9 \%$ and $21.5 \%$ for obesity and overweight, respectively (Figure 1).

The obesity prevalence was higher in women than men having a value of $13(5.6 \%)$ for women and one $(0.4 \%)$ for men. The same thing was also true for overweight; $22.1 \%$ prevalence was seen in women and $20.9 \%$ in men (Figure 1).

Sex and obesity were associated in the study population $(P=0.01)$ (Table 2$)$. The prevalence of obesity was higher in older age groups when compared to younger groups. The highest prevalence of obesity was observed in the age group of 45-54 years being $9.5 \%$. The same thing was also true for overweight; the highest prevalence of overweight was observed in the age group of $45-54$ years being $46.2 \%$ (Table 2). The prevalence of obesity was highest in the merchants with the value of $9(6.2 \%)$ followed by housewives accounting for 2 (5.4\%). The lowest obesity level was seen in non-government employees which was one $(1.3 \%)$. The prevalence of obesity was highest among married people with the value of 10 (3.7\%). The prevalence of obesity was higher among those of the highest wealth tercile households (6.2\%) when compared to the lowest wealth tercile households $(0.6 \%)$. Family size and monthly income had no statistically significant association with obesity $(P>0.05)$ (Table 2$)$.

Sex and obesity were associated in the study population $(P<0.01)$ (Table 2$)$. The prevalence of obesity was higher in older age groups when compared to younger groups. The highest prevalence of obesity was observed in the age group of 45-54 years being 9.5\%. The same thing was also true for overweight; the highest prevalence of overweight was observed in the age group of 45-54 years being $46.2 \%$ (Table 2). The prevalence of obesity was highest in the merchant with the value of $9(6.2 \%)$ followed by housewives accounting for $2(5.4 \%)$. The lowest obesity level was seen in non-government employees which was one (1.3\%). The prevalence of obesity was highest among married people with the value of $10(3.7 \%)$. Prevalence of obesity was higher among those of the highest wealth tercile households (6.2\%) when compared to the lowest wealth tercile households $(0.6 \%)$. Family size and monthly income had no statistically significant association with obesity $(P>0.05)$ (Table 2$)$.

With regard to the educational status, obesity was seen to be higher among those who had not attended formal school $4(25 \%)$ followed by college degree $9(2.7 \%)$ and high school $1(1.7 \%)$. There was statistically significant association between the two variables $(P<0.01)$ (Table 3$)$.

Majority of the study participants were in the highest tercile of the dietary diversity score $349(72.1 \%)$ while only $36(7.4 \%)$ were in low tercile. When obesity was analyzed with regard to dietary diversity score, 12 (3.4\%) were obese among those who were in the highest tercile of dietary diversity score. Two (2\%) were in the medium tercile, and none of them were in the low tercile of the dietary diversity score, but there was no association detected between the two variables $(P>0.05)$ (Table 3$)$.

About 175 (36.2\%) of the study participants were engaged in both low-intensity activity tasks and moderate-
TABle 3: Prevalence of obesity by sex with age group, educational status, dietary diversity score, alcohol consumption, and total physical activity level among adults in Addis Ababa, Ethiopia.

\begin{tabular}{|c|c|c|c|}
\hline \multirow{2}{*}{ Variables $(n=484)$} & \multicolumn{2}{|c|}{ Nutritional status $(N=14)$} & \multirow[b]{2}{*}{$P$ value } \\
\hline & $\begin{array}{c}\text { Obese } \\
\text { Number (\%) }\end{array}$ & $\begin{array}{c}\text { Nonobese } \\
\text { Number (\%) }\end{array}$ & \\
\hline \multicolumn{4}{|l|}{ Male } \\
\hline $25-34$ & $0(0)$ & $125(100)$ & \multirow{4}{*}{$>0.05$} \\
\hline $35-44$ & $1(1.1)$ & $88(98.9)$ & \\
\hline $45-54$ & $0(0)$ & $19(70.4)$ & \\
\hline $55-64$ & $0(0)$ & $6(50)$ & \\
\hline \multicolumn{4}{|l|}{ Female } \\
\hline $25-34$ & $3(2.1)$ & $140(97.9)$ & \multirow{4}{*}{$>0.05$} \\
\hline $35-44$ & $4(6.6)$ & $57(93.4)$ & \\
\hline $45-54$ & $4(26.7)$ & $11(73.3)$ & \\
\hline $55-64$ & $2(16.7)$ & $10(83.3)$ & \\
\hline \multicolumn{4}{|l|}{ Educational status } \\
\hline No school & $4(25)$ & $12(75)$ & \multirow{5}{*}{$<0.0001$} \\
\hline Elementary & $0(0)$ & $43(100)$ & \\
\hline Junior & $0(0)$ & $29(100)$ & \\
\hline High school & $1(1.7)$ & $58(98.3)$ & \\
\hline College and above & $9(2.7)$ & $328(97.3)$ & \\
\hline \multicolumn{4}{|c|}{ Dietary diversity score } \\
\hline Low $(0-3)$ & $0(0)$ & $36(100)$ & \multirow{3}{*}{$>0.05$} \\
\hline Medium (4-5) & $2(2)$ & $97(98)$ & \\
\hline High $(\geq 6)$ & $12(3.4)$ & $337(96.6)$ & \\
\hline \multicolumn{4}{|c|}{ Total physical activity level (TPAL) } \\
\hline Highly active & $1(0.7)$ & 133 (99.3) & \multirow{3}{*}{$<0.0001$} \\
\hline Moderately active & $12(6.9)$ & $163(93.1)$ & \\
\hline Sedentary & $1(0.6)$ & $174(99.4)$ & \\
\hline \multicolumn{4}{|c|}{ Average daily alcohol consumption } \\
\hline$\leq 1$ beer a day & $9(5.5)$ & $154(94.5)$ & \multirow{2}{*}{$>0.007$} \\
\hline$>1$ beer a day & $0(0)$ & $128(100)$ & \\
\hline \multicolumn{4}{|c|}{ Currently consumed alcohol } \\
\hline Yes & $9(3)$ & $290(97)$ & \multirow{2}{*}{$>0.05$} \\
\hline No & $5(2.7)$ & $180(97.3)$ & \\
\hline
\end{tabular}

$P$ values refer to the chi-squared test for the difference observed between obese and nonobese participants.

intensity activity, and the rest $134(27.7 \%)$ were engaged in high-intensity activity. Larger proportions, 12 (6.9\%), of the obese were engaged in moderate-intensity activity and one $(0.6 \%)$ was on sedentary activity (Table 3 ).

3.3. Prevalence of Hypertension and Diabetes Mellitus with Obesity. With regard to the smoking status, there was no significant association between obesity and current or previous (who have stopped smoking) smoking habits. From $362(74.8 \%)$ of the study participants who have had their blood pressure measured, 44 (12.2\%) were hypertensive.

From the total obesity in the study population, 4 (9.1\%) were hypertensive according to the report by the respondents. From 227 (46.9\%) of the study participants who have had their blood sugar level measured, 21 (9.3\%) were diabetic. From the total obese study participants, one (4.8\%) was diabetic. Hypertension and obesity were associated in the study population $(P<0.05)$, but there was no 
TABLE 4: Prevalence of hypertension and diabetes mellitus in adults of Addis Ababa who have had their blood sugar level and blood pressure measured by obesity.

\begin{tabular}{|c|c|c|c|c|}
\hline \multirow[b]{2}{*}{ Variables } & \multicolumn{2}{|c|}{ Nutritional status $(N=14)$} & \multirow[b]{2}{*}{ COR $(95 \% \mathrm{CI})$} & \multirow[b]{2}{*}{ AOR $(95 \% \mathrm{CI})$} \\
\hline & $\begin{array}{c}\text { Obese } \\
\text { Number (\%) }\end{array}$ & $\begin{array}{c}\text { Nonobese } \\
\text { Number (\%) }\end{array}$ & & \\
\hline \multicolumn{5}{|c|}{ Hypertension } \\
\hline No & $8(2.5)$ & $310(97.5)$ & $0.26(0.07-0.89)^{*}$ & $0.14(0.03-0.69)^{*}$ \\
\hline Yes & $4(9.1)$ & $40(90.9)$ & 1.00 & 1.00 \\
\hline Total & $12(3.3)$ & $350(96.7)$ & - & - \\
\hline \multicolumn{5}{|c|}{ Taking hypertensive drugs } \\
\hline No & $10(3)$ & $322(97)$ & - & $>0.05$ \\
\hline Yes & $2(6.7)$ & $28(93.3)$ & - & - \\
\hline \multicolumn{5}{|c|}{ Diabetes mellitus (DM) } \\
\hline No & $9(4.4)$ & $197(95.6)$ & $0.91(0.11-7.59)$ & - \\
\hline Yes & $1(4.8)$ & $20(95.2)$ & 1.00 & - \\
\hline Total & $10(4.4)$ & $217(95.6)$ & - & - \\
\hline \multicolumn{5}{|c|}{ Taking DM drugs } \\
\hline No & $9(4.2)$ & $203(95.8)$ & - & $>0.05$ \\
\hline Yes & $1(7.7)$ & $12(92.3)$ & - & - \\
\hline
\end{tabular}

TABLE 5: Multivariable logistic regression model predicting obesity among adults in Addis Ababa, Ethiopia.

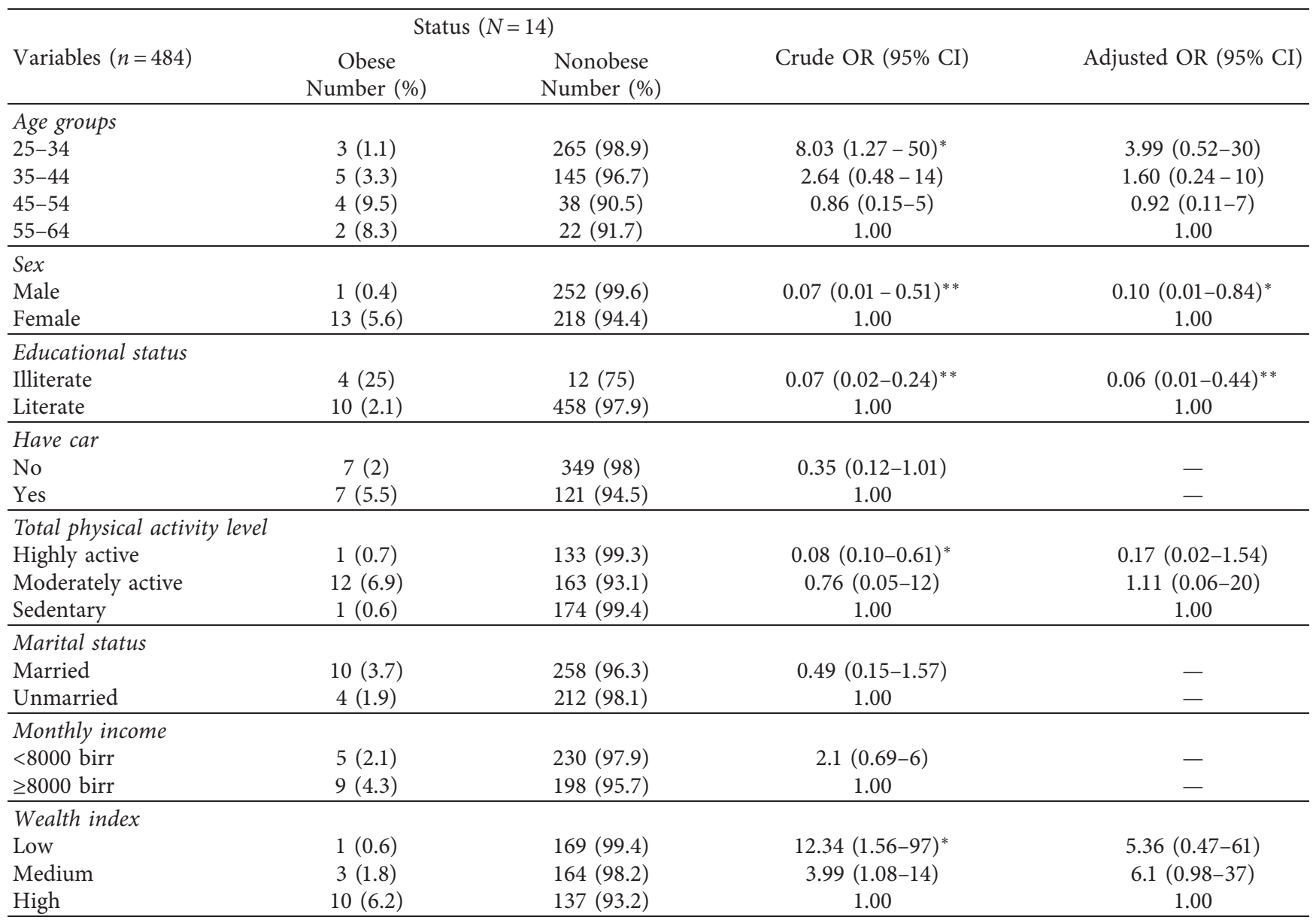

${ }^{* *} P<0.01 ;{ }^{*} P<0.05$. 
association detected between obesity and diabetes mellitus (Table 4).

3.4. Factors Associated with Obesity. From the multivariable logistic regression analysis, history of hypertension, sex, and educational status were significantly associated with being overweight and obese. Nonhypertensive individuals were $86 \%$ less likely to be obese when compared to hypertensive $(\mathrm{AOR}=0.14(95 \% \mathrm{CI}: 0.03-0.69))$ (Table 4). Males were $90 \%$ less likely to be obese when compared to females $(\mathrm{AOR}=0.10$ (95\% CI: 0.01-0.84)). Illiterate people were $94 \%$ less likely to be obese compared to those who were literate people $(\mathrm{AOR}=0.06$ (95\% CI: 0.01-0.44)) (Table 5).

\section{Discussion}

A community-based cross-sectional study was conducted in Addis Ababa residents to determine the prevalence and associated factors of overweight/obesity. The prevalence of obesity is an emerging problem in Ethiopia. In the setting of the study population, female sex, educational status, and hypertension were found to be significantly associated with overweight and obesity. In this study, female sex, educational status, and hypertension were found to be significantly associated with overweight and obesity. In the current finding, women were more likely to be overweight/obese as compared to men. The current study is similar with the studies conducted in Ghana and Ethiopia [24, 25]. This might be due to the fact that women have more adipose tissues than men, and they are also exposed to more sedentary life style, and high-energy foods are usually consumed. The current study showed that literate people were more likely to be obese than uneducated people. According to the national DHS, overweight/obesity increases with education level. Similarly, those who have more than secondary education were four times as likely to be overweight or obese as compared with noneducated $[9,26]$. This could be due to the fact that educated people are likely to consume better intake of high-fat and high-calorie diet and follow a sedentary life style, so they increase to be overweight and obese. In this study, the presence of hypertension was associated with obesity. Most studies have investigated the relationship between obesity and hypertension. People with obesity are more likely to have hypertension. Obesity is also associated with an increased cardiovascular risk and earlier onset of morbidity. The growing obesity emergence is one of the major sources of unsustainable health costs and morbidity and mortality due to hypertension [11, 27].

The study was community-based approach, and it may represent the prevalence of problem in the community. This study is based on the reported morbidities but not based on the results from laboratory or clinical diagnosis. There may be recall bias in reporting different food groups consumed over the previous day in the dietary diversity score. The study also does not assess the daily caloric intake of the study participants which could have its effect on obesity. The physical activity tool was not validated for the study population and may have under- or overestimated the main findings.

\section{Conclusions}

This study revealed an emerging problem of a high prevalence of overweight and obesity among adults of Addis Ababa residents at which the combined prevalence of overweight and obesity was found to be considerably high in Addis Ababa city residents compared to the national figure. Independent predictors of overweight/obesity in the population studied were female sex, educational status, and presence of hypertension. Various health sectors should give special emphasis to women, educated people, and prevention of hypertension as the problem of obesity prevails. They should have to enlighten the educated people on the importance of active lifestyle and regular physical exercise for the maintenance of good body size and health. In general, a thorough nutrition education or behavior change communication on obesity and its consequences has to be addressed to the study population. In addition, the concerned bodies should initiate efforts to tackle the newly emerging public health problem of the country and promote healthy lifestyle behaviors in the inhabitants of city settings.

\section{Data Availability}

The data used to support the findings of this study are available from the corresponding author upon request.

\section{Ethical Approval}

The ethical approval was obtained from the Ethical Review Committee of the St. Paul's Hospital Millennium Medical College (SPHMMC).

\section{Consent}

An informed consent was obtained from the participants' parents before being enrolled in the study. In addition, participants were assured about the aim, possible risk if any, and confidentiality of the study using their own local language (Amharic).

\section{Disclosure}

The funding body had no influence on study design, data collection, analysis and interpretation of data, writing of the manuscript, and in the decision to submit the manuscript for publication.

\section{Conflicts of Interest}

The authors declare that they have no conflicts of interest regarding the publication of this paper.

\section{Authors' Contributions}

TW, SS, AG, and HE contributed to conception and design, acquisition of data, or analysis and interpretation of data. All authors contributed to data analysis, drafting, or revising the manuscript, gave final approval of the version to be 
published, and agreed to be accountable for all aspects of the work.

\section{Acknowledgments}

The authors would like to express their sincere gratitude to St. Paul's Hospital Millennium Medical College (SPHMMC) for their financial and technical support, study participants, and all individuals who rendered help during the study period. The authors would also like to express their deepest sorrow for the loss of the PI, Tsedeke Wolde Hailemariam, during the peer review time and they would also like to dedicate this publication in memory of him.

\section{References}

[1] F. Timothy, "World wide survey finds adult obesity rate of around 25\% Clinical psychiatry news," Journal of Nutrition, vol. 36, no. 3, 12 pages, 2008.

[2] E. Perez-Then, A. Campa, M. Miguez-Burbano et al., "Obesity and HIV-1 disease progression with and without HAART," in International Conference on AIDS, National Institutes of Health, Durban, South Africa, January 2000.

[3] B. M. Popkin, "The nutrition transition and obesity in the developing world," The Journal of Nutrition, vol. 131, no. 3, pp. 871s-873s, 2001.

[4] B. Popkin, The Nutrition Transition and Obesity in Developing World Differs from Past Experiences, University of North California, Chapel Hill, NC, USA, 2002.

[5] R. Ostwald, "Westernization of diet and serum lipids in Ethiopians," The American Journal of Clinical Nutrition, vol. 31, no. 6, pp. 1028-1040, 1978.

[6] B. Gebre-Medhin, The World Food Situation. New Driving Forces and Required Actions, International Food Policy Research Institute, Washington, D.C, 2007.

[7] World Health Organization (WHO), Obesity. Preventing and Managing the Global Epidemic. Report of WHO Consultation on Obesity 3-5th June 1997, WHO, Geneva, Switzerland, 2011.

[8] Central Statistical Agency/Ethiopia and ICF International, Ethiopia Demographic and Health Survey 2011, Central Statistical Agency/Ethiopia and ICF International, Addis Ababa, Ethiopia, 2012, http://dhsprogram.com/pubs/pdf/FR255/ FR255.pdf.

[9] Central Statistical Agency-CSA/Ethiopia and ICF, Ethiopia Demographic and Health Survey 2016, CSA and ICF, Addis Ababa, Ethiopia, 2017, http://dhsprogram.com/pubs/pdf/ FR255/FR255.pdf.

[10] S. Abrha, S. Shiferaw, and K. Y. Ahmed, "Overweight and obesity and its sociodemographic correlates among urban Ethiopian women: evidence from the 2011 EDHS," BMC Public Health, vol. 16, no. 1, p. 636, 2016.

[11] B. Moges, B. Amare, B. Fantahun, and A. Kassu, "High prevalence of overweight, obesity, and hypertension with increased risk to cardiovascular disorders among adults in northwest Ethiopia: a cross sectional study," BMC Cardiovascular Disorders, vol. 14, p. 155, 2014.

[12] M. Shegaze, M. Wondafrash, A. A. Alemayehu et al., "Magnitude and determinants of overweight and obesity among high school adolescents in Addis Ababa, Ethiopia," Journal of Food and Nutrition Sciences, vol. 3, no. 5, pp. 166-173, 2015.
[13] Y. Tebekaw, C. Teller, and U. Colón-Ramos, "The burden of underweight and overweight among women in Addis Ababa, Ethiopia," BMC Public Health, vol. 14, p. 1126, 2014.

[14] G. A. Shayo and F. M. Mugusi, "Prevalence of obesity and associated risk factors among adults in Kinondoni municipal district, Dar es salaam Tanzania," BMC Public Health, vol. 11, no. 365, 2011.

[15] K. P. Msyamboza, D. Kathyola, and T. Dzowela, "Anthropometric measurements and prevalence of underweight, overweight and obesity in adult Malawians: nationwide population based NCD STEPS survey," Pan African Medical Journal, vol. 15, no. 1, 2013.

[16] D. Samuel, A. G. Yalemzewod, A. Zegeye et al., "Factors associated with overweight and obesity among adults in northeast Ethiopia: a cross- sectional study," Diabetes, Metabolic Syndrome and Obesity: Targets and Therapy, vol. 12, pp. 391-399, 2019.

[17] T. Darebo, A. Mesfin, and S. Gebremedhin, "Prevalence and factors associated with overweight and obesity among adults in Hawassa city, southern Ethiopia: a community based crosssectional study," BMC Obesity, vol. 6, no. 8, 2019.

[18] T. Mekonnen, W. Animaw, and Y. Seyum, "Overweight/ obesity among adults in North-Western Ethiopia: a community-based cross sectional study," Archives of Public Health, vol. 76, p. 18, 2018.

[19] Bereket, "Prevalence of metabolic syndrome among working adults in Ethiopia," International Journal of Hypertension, vol. 2011, p. 8, Article ID 193719, 2011.

[20] Central Statistical Agency, Summary and Statistical Report of the 2007 Population and Housing Census of Ethiopia, Central Statistical Agency, Addis Ababa, Ethiopia, 2008.

[21] WHO, The WHO STEP Wise Approach to Chronic Disease Risk Factor Surveillance (STEPS), World Health Organization, Geneva, Switzerland, 2008.

[22] Food and Agriculture Organization (FAO), Guidelines for Measuring Household and Individual Dietary Diversity. FAO Nutrition and Consumer Protection Division, with Support from the EC/FAO Food Security Information for Action Programme and the Food and Nutrition Technical Assistance (FANTA) Project, Food and Agriculture Organization (FAO), Rome. Italy, 2008.

[23] R. Gibson, Priniples of Nutritional Assessment, Oxford Universty Press, Oxford, UK, 2005.

[24] A. R. Abubakari, W. Lauder, C. Agyemang, M. Jones, A. Kirk, and R. S. Bhopal, "Prevalence and time trends in obesity among adult West African populations: a meta-analysis," Obesity Reviews, vol. 9, no. 4, pp. 297-311, 2008.

[25] E. Alemu, A. Atnafu, M. Yitayal et al., "Prevalence of overweight and/or obesity and associated factors among high school adolescents in arada sub city, Addis Ababa, Ethiopia," Journal of Nutrition \& Food Sciences, vol. 4, p. 261, 2014.

[26] S. Subramanian, J. M. Perkins, E. Özaltin, and G. Davey Smith, "Weight of nations: a socioeconomic analysis of women in low- to middle-income countries," The American Journal of Clinical Nutrition, vol. 93, no. 2, pp. 413-421, 2011.

[27] M. Leggio, M. Lombardi, E. Caldarone et al., "The relationship between obesity and hypertension: an updated comprehensive overview on vicious twins," Hypertension Research, vol. 40, no. 12, pp. 947-963, 2017. 